\title{
Synaptic Depotentiation and mGluR5 Activity in the Nucleus Accumbens Drive Cocaine-Primed Reinstatement of Place Preference
}

\author{
Michael A. Benneyworth, ${ }^{1,2 *}$ Matthew C. Hearing, ${ }^{3 *}{ }^{\circledR}$ Anders J. Asp, ${ }^{1}$ Aric Madayag, ${ }^{3}{ }^{\circledR}$ Anna E. Ingebretson, ${ }^{1}$ \\ Clare E. Schmidt, ${ }^{1}$ Keelia A. Silvis, ${ }^{1}{ }^{\circ}$ Erin B. Larson, ${ }^{1}$ Stephanie R. Ebner, ${ }^{1}$ and ${ }^{\oplus M a r k ~ J . ~ T h o m a s ~}{ }^{1}$ \\ ${ }^{1}$ Department of Neuroscience, ${ }^{2}$ Mouse Behavior Core, University of Minnesota, Minneapolis, Minnesota 55455, and ${ }^{3}$ Department of Biomedical Sciences, \\ Marquette University, Milwaukee, Wisconsin 53233
}

Understanding the neurobiological processes that incite drug craving and drive relapse has the potential to help target efforts to treat addiction. The NAc serves as a critical substrate for reward and motivated behavior, in part due to alterations in excitatory synaptic strength within cortical-accumbens pathways. The present studies investigated a causal link between cocaine-induced reinstatement of conditioned place preference and rapid reductions of cocaine-dependent increases in NAc shell synaptic strength in male mice. Cocaineconditioned place preference behavior and ex vivo whole-cell electrophysiology showed that cocaine-primed reinstatement and synaptic depotentiation were disrupted by inhibiting AMPAR internalization via intra-NAc shell infusion of a Tat-GluA2 ${ }_{3 \mathrm{Y}}$ peptide. Furthermore, reinstatement was driven by an mGluR5-dependent reduction in AMPAR signaling. Intra-NAc shell infusion of the mGluR5 antagonist MTEP blocked cocaine-primed reinstatement and corresponding depotentiation, whereas infusion of the mGluR5 agonist CHPG itself promoted reinstatement and depotentiated synaptic strength in the NAc shell. Optogenetic examination of circuit-specific plasticity showed that inhibition of infralimbic cortical input to the NAc shell blocked cocaine-primed reinstatement, whereas low-frequency stimulation $(10 \mathrm{~Hz})$ of this pathway in the absence of cocaine triggered a reduction in synaptic strength akin to that observed with cocaine, and was sufficient to promote reinstatement in the absence of a cocaine challenge. These data support a model in which mGluR5mediated reduction in GluA2-containing AMPARs at NAc shell synapses receiving input from the infralimbic cortex is a critical factor in triggering reinstatement of cocaine-primed conditioned approach behavior.

Key words: AMPAR; cocaine; long-term depression; optogenetics; relapse; synaptic plasticity

Significance Statement

These studies identified a sequence of neural events whereby reexposure to cocaine activates a signaling cascade that alters synaptic strength in the NAc shell and triggers a behavioral response driven by a drug-associated memory.

\section{Introduction}

Drug relapse following periods of abstinence is a major obstacle in our ability to effectively treat addiction. Preceding relapse,

Received Oct. 19, 2017; revised March 1, 2019; accepted March 26, 2019

Author contributions: M.A.B., M.C.H., and M.J.T. designed research; M.A.B., M.C.H., A.J.A., A.M., A.E.I., C.E.S., K.A.S., E.B.L., and S.R.E. performed research; M.A.B., M.C.H., A.J.A., A.M., A.E.I., and E.B.L. analyzed data; M.A.B., M.C.H., and M.J.T. wrote the paper; M.J.T. edited the paper.

This work was supported by National Institute on Drug Abuse Grants R01 DA019666, K02 DA035459, and R01 DA041808 to M.J.T., K99 DA038706 to M.C.H., and T32 DA007234 to A.E.I. and S.R.E. Behavioral studies were supported by the University of Minnesota Mouse Behavior Core, with funding from the National Institute for Neurological Disorders and Stroke P30 NS062158 to M.A.B. and M.J.T. We thank the MnDRIVE Optogenetics Core at the University of Minnesota for providing invaluable technical support for the neuromodulation studies.

The authors declare no competing financial interests.

*M.A.B. and M.C.H. contributed equally to this work.

Correspondence should be addressed to Mark J. Thomas at tmhomas@umn.edu. many addicts experience intense craving precipitated by drug reexposure, or exposure to drug-associated contextual cues (Jaffe et al., 1989; Ehrman et al., 1992; Childress et al., 1999; Bossert et al., 2013). However, our limited understanding of how neural plasticity evoked by exposure to relapse-linked stimuli elicits relapse-related behavior has hampered our ability to effectively confront addiction.

The NAc is critically involved in the attribution of incentive motivation and acquisition and expression of reward-dependent behavior (Kalivas and Volkow, 2005; Hyman et al., 2006). The principal cells in the NAc are GABAergic medium spiny neurons (MSNs), which receive convergent dopaminergic and glutama- 
tergic input arising from numerous brain regions (O'Donnell and Grace, 1995; Finch, 1996; Zahm, 2000; Horvitz, 2002; Floresco, 2007; Britt et al., 2012). Repeated exposure to psychostimulants drives an enduring increase in excitatory synaptic strength onto NAc MSNs, mediated by AMPA-type glutamate receptors (Kourrich et al., 2007; Conrad et al., 2008; Dobi et al., 2011; Pascoli et al., 2011, 2014; Rothwell et al., 2011; Britt et al., 2012; Jedynak et al., 2016; Ebner et al., 2018). Accumulating evidence supports the idea that this plasticity, which is accompanied by an upregulation of AMPAR surface expression (Boudreau and Wolf, 2005; Boudreau et al., 2007; Conrad et al., 2008), is a key neural adaptation underlying the development and persistence of addiction-related behavior (Pierce and Wolf, 2013); reexposure to psychostimulants or relapse-linked stimuli, such as stress during abstinence, produces a rapid reduction of AMPAR signaling and effectively reverses this potentiation, suggesting the possibility that this experience-dependent AMPAR plasticity may act as a synaptic trigger for driving relapse (Kourrich et al., 2007; Famous et al., 2008; Rothwell et al., 2011; Jedynak et al., 2016; Ebner et al., 2018).

The shell region of the NAc plays a critical role in developing conditioned drug associations that can drive relapse to cocaine seeking (Rogers et al., 2008; Pierce and Wolf, 2013) Excitatory synapses on NAc shell MSNs are capable of activity-dependent long-term plasticity via decreases in AMPAR signaling (Thomas et al., 2000, 2001; Brebner et al., 2005; Pascoli et al., 2011, 2014; Creed et al., 2015). While the existence of this plasticity was first established with exogenous electrical stimulation, it is now known that reduced synaptic strength in the NAc shell is a common synaptic adaptation induced by multiple experiences known to cause reinstatement, including stress, drug, or drug-paired cue reexposure (Thomas et al., 2001; Kourrich et al., 2007; Rothwell et al., 2011; Jedynak et al., 2016; Ebner et al., 2018). Reductions in synaptic strength produced by a cocaine priming injection have been shown, ex vivo, to involve reductions in AMPAR signaling, an effect that was blocked by antagonism of the Group 1 metabotropic glutamate receptor, mGluR5 (Jedynak et al., 2016). NAc shell mGluR5 activation has also been shown to play a significant role in drug-induced reinstatement of cocaine seeking (Schmidt et al., 2013). Reinstatement of drug seeking was also associated with increased phosphorylation of the GluA2 AMPAR subunit at Ser880, a PKC phosphorylation site that is known to promote endocytosis of GluA2-contianing AMPARs (Schmidt et al., 2013). These studies independently suggest that reinstatement of drug seeking relies on a rapid mGluR5-dependent endocytosis of AMPAR signaling; however, a direct causal link between mGluR5-dependent reductions in AMPAR signaling, AMPAR endocytosis, and behavior induced by a cocaine challenge injection has yet to be investigated. The present study combined targeted pharmacological manipulation of mGluR5 signaling, optogenetics, and whole-cell electrophysiology to directly examine the causal link between cocaine-induced bidirectional plasticity in the NAc shell and the reinstatement of reward-seeking driven by conditioned contextual associations.

\section{Materials and Methods}

Animals. Adult (P48-P60) male C57BL/6J mice (The Jackson Laboratory) were group housed on a $12 \mathrm{~h}$ light/dark cycle with food and water available ad libitum. All experiments were approved by the University of Minnesota Institutional Animal Care and Use Committee.

Stereotaxic intracranial cannula implantation. Before surgery, mice were anesthetized with a mixture of ketamine and xylazine (100 and 10 $\mathrm{mg} / \mathrm{kg}$, respectively, i.p.). Depth of anesthesia was assessed before the subject being placed in the stereotaxic frame (Kopf Instruments). After exposure of the skull, cranial landmarks were identified, the skull was leveled with respect to bregma and lambda, and the points of implant were identified (for NAc shell targeting: 1.50 anteroposterior, \pm 1.45 mediolateral; for NAc core targeting: 1.35 anteroposterior, \pm 2.1 mediolateral; all in $\mathrm{mm}$ with respect to bregma or midline). Single-barrel guide cannulae (26 gauge, $5 \mathrm{~mm}$ pedestal, $3.5 \mathrm{~mm}$ projection; C315GS-5/SP, Plastics One) were implanted at a $14^{\circ}$ angle, lowered to a depth of -4.0 $\mathrm{mm}$ ventral to skull, cranial screws were attached to skull, and the cannulae were cemented in place using Geristore (DenMat). Mice were then moved to the recovery area for observation. Behavioral testing started 7-17 d after surgery.

Virus stereotaxic injection and fiber optic implantation. AAV8CaMKII $\alpha$-Jaws-KGC-GFP-ER2 or AAV2-CaMKII $\alpha$-ChR2(H134R)eYFP (UNC Vector Core, Chapel Hill, NC) was injected into the infralimbic cortex (ILC) of mice using stereotaxic techniques described above. Targeting coordinates were 1.75 anteroposterior, \pm 0.4 mediolateral, and -3.1 dorsoventral; all in $\mathrm{mm}$ with respect to bregma); $0.5 \mu \mathrm{l}$ of virus solution was injected into each side over $5 \mathrm{~min}$. The injection needle was left in place for $5 \mathrm{~min}$ after infusion and then slowly withdrawn to reduce backflow. Approximately 6 weeks after viral infection, mice were implanted with fiber optics (200/230 $\mu \mathrm{m}$ core/cladding, $0.66 \mathrm{NA})$ that terminated $0.5 \mathrm{~mm}$ above the NAc shell. Optic fibers were restrained using zirconia ferrules that were cemented to the skull with cranial screws and Geristore resin.

Conditioned place preference (CPP). All CPP experiments used a twochamber apparatus as previously described (Wydeven et al., 2014), using "rod" and "mesh" floor inserts as discriminative contextual cues. All data were collected by video cameras, and exploration was analyzed by ANYmaze software (Stoelting). Preconditioning exploration bias was determined in a 20 min "pretest." No general chamber bias was observed, so drug-chamber (US-CS) pairings were randomly assigned and counterbalanced to ensure no pretest preference or aversion in each test group. Conditioning was conducted over $4 \mathrm{~d}$ using daily, alternating sessions of saline or cocaine ( $7.5 \mathrm{mg} / \mathrm{kg}$; s.c, $10 \mathrm{ml} / \mathrm{kg}$ injection volume.). This provides $2 \mathrm{~d}$ of cocaine treatment and $2 \mathrm{~d}$ of saline treatment. Injections were performed immediately before conditioning. Twenty-four hours following the final conditioning session, mice were given a 20 min free choice test to assess place preference. Place preference was determined by calculating the difference in time spent in the $\mathrm{CS}^{+}$(drug-paired) and $\mathrm{CS}^{-}$ (drug-unpaired) chambers during the test sessions; "preference" is defined as $\mathrm{CS}^{+}-\mathrm{CS}^{-}$within a given test session. Following preference testing, mice underwent 6 daily extinction sessions. On day 1,3 , and 5 , animals were confined to the $\mathrm{CS}^{+}$and $\mathrm{CS}^{-}$compartment for $20 \mathrm{~min}$ each (extinction training). On day 2, 4, and 6, animals were allowed free exploration of both compartments for $20 \mathrm{~min}$, and movement was recorded to track extinction (extinction testing). Data obtained on extinction Test 3 were used in two-way repeated-measures ANOVA. Three of these $2 \mathrm{~d}$ blocks are necessary to develop a stable neutral preference score.

Reinstatement of place preference. Experimental treatments for the reinstatement tests were assigned after extinction training, and assignments were made to ensure that treatment groups had similar preference scores before and following extinction. Reinstatement of place preference was performed in five different experiments.

Cocaine-primed reinstatement: Immediately before preference testing, animals were injected with either cocaine $(7.5 \mathrm{mg} / \mathrm{kg}$, s.c.) or saline, then placed into the test chamber. Preference behavior was recorded and analyzed for $20 \mathrm{~min}$.

Intra-NAc GluA2 peptide: To block endocytosis of GluA2-containing AMPARs in the NAc shell, a fluorescently tagged (eGFP) synthetic interference peptide was intracranially infused before a cocaine or saline challenge injection for reinstatement of place preference as previously described (Brebner et al., 2005). Mice were infused with the active or inactive version of the peptide, referred to as Tat-GluA2 $2_{3 Y}$ or TatGluA2 $2_{3 \mathrm{~A}}$, respectively. The active Tat-GluA2 $2_{3 \mathrm{Y}}$ is designed to disrupt activity-dependent endocytosis without affecting basal receptor trafficking, while the inactive Tat-GluA2 ${ }_{3 \mathrm{~A}}$ has been shown to have no effect on AMPAR signaling or function (Brebner et al., 2005). These peptides were diluted in ACSF and bilaterally infused into the NAc shell (75 pmol; 0.5 $\mu \mathrm{l} / \mathrm{hemisphere;} 0.1 \mu \mathrm{l} / \mathrm{min}$ ) using a 32 gauge internal cannula with 1.2 
$\mathrm{mm}$ projection beyond the guide. Following infusions, mice were returned to their home cage for $60 \mathrm{~min}$, at which point they received a subcutaneous injection of cocaine $(7.5 \mathrm{mg} / \mathrm{kg})$ or saline, followed by examination of preference behavior during a 20 min test. A similar experiment was performed with infusions of these peptides into the NAc core to examine the anatomical specificity for AMPAR endocytosis to control cocaine-primed reinstatement.

Intra-NAc mGluR5 blockade/activation: In these experiments, mice received bilateral intra-NAc shell microinfusions of the mGluR5 selective antagonist, 3-((2-Methyl-1,3-thiazol-4-yl)ethynyl)pyridine (MTEP, Tocris Bioscience), the mGluR5 selective agonist, (R,S)-2-chloro-5hydroxyphenylglycine (CHPG, Tocris Bioscience), or vehicle (ACSF) before reinstatement testing via a microinjector inserted into the indwelling guide cannulae. In both cases, $0.5 \mu \mathrm{l} /$ hemisphere was infused at $0.1 \mu \mathrm{l} /$ $\mathrm{min}$, followed by a $5 \mathrm{~min}$ postinfusion wait period before removing the injector, after which mice were returned to their home cage for $20 \mathrm{~min}$ before receiving an injection of cocaine or saline, and preference reinstatement testing was performed as described above. Multiple doses of $\operatorname{MTEP}(1,3 \mu \mathrm{g})$ and CHPG $(0,1,3$ or $6 \mu \mathrm{g})$ were tested.

In vivo optogenetic neuromodulation: For the neural inhibition (adenoassociated virus $[\mathrm{AAV}]$-Jaws) experiments, immediately before testing, mice were connected to indwelling optical fibers for delivery of red light via LED sources (Plexon, $630 \mathrm{~nm}, \sim 7 \mathrm{~mW}$ ). Mice were then given injections of cocaine $(7.5 \mathrm{mg} / \mathrm{kg}$, s.c. $)$ or saline and placed in the test chamber. LED lights were activated before the injection and remained on for the duration of the test session $(20 \mathrm{~min})$. Test groups included cocaine injected in the presence and absence of red-light stimulation of Jaws, and well as a control group that received a saline injection and red-light stimulation of Jaws. For neural stimulation (AAV-channelrhodopsin [ChR2]) experiments, immediately before testing, mice were connected to indwelling optical fibers for delivering blue light via LED sources (Plexon, $465 \mathrm{~nm}, \sim 10-15 \mathrm{~mW}$ ). All mice in these experiments received an intra-ILC infusion of ChR2 and were divided into groups receiving light stimulation $(10 \mathrm{~Hz}, 5 \mathrm{~ms}$ pulse width) or no light stimulation, which was performed in the place conditioning test chamber immediately following placement of animal in the chamber for the first $5 \mathrm{~min}$ of the 20 min test session. No saline or cocaine injections were given for these experiments.

Electrophysiology. Within $2 \mathrm{~h}$ of completing the last behavioral (reinstatement) test, mice were anesthetized with isoflurane and $250 \mu \mathrm{m}$ sagittal slices containing the NAc shell were prepared as previously described (Hearing et al., 2016). Slices recovered for at least $30 \mathrm{~min}$ in ACSF solution saturated with $95 \% \mathrm{O}_{2} / 5 \% \mathrm{CO}_{2}$ containing the following (in $\mathrm{mm}$ ): $119 \mathrm{NaCl}, 2.5 \mathrm{KCl}, 1.0 \mathrm{NaH}_{2} \mathrm{PO}_{4}, 1.3 \mathrm{MgSO}_{4}, 2.5 \mathrm{CaCl}_{2}, 26.2 \mathrm{NaHCO}_{3}$, and 11 glucose. Electrophysiological recordings assessing AMPAR/ $\operatorname{NMDAR}(\mathrm{A} / \mathrm{N})$ ratios and mEPSCs were performed in the presence of picrotoxin and lidocaine, respectively, as previously described (Hearing et al., 2016; Jedynak et al., 2016) to block GABAergic neurotransmission and action potentials, respectively. Cells were visualized in sagittal slices using infrared-differential contrast microscopy, and MSNs were identified by their morphology, membrane resistance, capacitance, and hyperpolarized resting potential $(-70$ to $-80 \mathrm{mV}$, correcting for junction potential). Using a Multiclamp 700B (Molecular Devices), MSNs were voltage-clamped at $-80 \mathrm{mV}$ using electrodes $(3-5 \mathrm{M} \Omega$ ) containing a cesium-gluconate based internal solution previously described (Kourrich et al., 2007). Data were filtered by the amplifier at $2 \mathrm{kHz}$ and digitized at $5 \mathrm{kHz}$ via custom Igor Pro software (Wavemetrics). Series resistance $(10-40 \mathrm{M} \Omega)$ and input resistance $(>400 \mathrm{M} \Omega)$ were monitored using a depolarizing step ( $4 \mathrm{mV}, 100 \mathrm{~ms}$ ) generated by a Master- 8 stimulator. For AMPAR/NMDAR and mEPSCs measurements, data collection and analysis were performed as previously described (Kourrich et al., 2007; Hearing et al., 2016). For optogenetic experiments, light-EPSCs were evoked with blue light pulses through a submerged $40 \times$ objected directed at the NAc shell that was coupled to a SOLA LED Light Engine (Lumencor) and a GFP filter. Low-frequency $(10 \mathrm{~Hz})$ stimulation was applied with $5 \mathrm{~ms}$ light pulses, and the magnitude of LTD was determined by comparing average sEPSCs that were recorded 10-20 min after induction to sEPSCs recorded immediately before induction. Optical stimulation was per- formed in the presence of ACSF or following $10 \mathrm{~min}$ of bath applied MTEP $(10 \mu \mathrm{m})$.

Drugs. Picrotoxin and lidocaine were purchased from Sigma-Aldrich. D-AP5, CHPG, and MTEP was purchased from Tocris Biosciences. Cocaine $\mathrm{HCl}$ (Medisca) was obtained through Boynton Pharmacy (University of Minnesota, Minneapolis).

Histological analysis. Postmortem histological examination of cannula, fiber, and virus targeting was done in PFA ( $4 \%$ in buffered saline) fixed tissue. For tissue fixation, animals were given an overdose of pentobarbital $(650 \mathrm{mg} / \mathrm{kg}$, i.p.) and transcardially perfused with buffered saline followed by PFA solution. Brains were removed, cryoprotected, and later sliced at $40 \mu \mathrm{m}$. Sections were mounted, washed with buffered saline, and coverslipped with ProLong gold antifade mounting medium (Invitrogen). Tissue was visualized to confirm targeting to the anticipated regions.

Statistical analysis and notes on data presentation. AMPAR/NMDAR ratios and mEPSCs were analyzed with a Student's $t$ test, one-way or two-way ANOVA using SigmaPlot (Systat Software) or Graph Pad Prism (GraphPad Software). Newman-Keuls post hoc tests were used for pairwise comparisons when appropriate. Behavioral test sessions were analyzed with one-way and two-way ANOVAs with post hoc $t$ test comparisons between groups (Bonferroni or Dunnett where applicable). Nonparametric analysis (Kruskal-Wallis with Dunn post hoc $t$ test) was used where data violated ANOVA assumptions of normality (Fig. 1). Optical stimulation experiments were a two-sample comparison analyzed with a paired Student's $t$ test. The threshold for statistical significance in all cases was $p<0.05$. All data are represented using standard column graphs displaying mean \pm SEM, with adjacent scatter plots of individual data points.

\section{Results}

\section{Bidirectional changes in AMPAR-mediated synaptic transmission in the NAc shell}

Cocaine-induced plasticity at NAc shell MSNs has been shown to exhibit bidirectional characteristics. For example, while excitatory synaptic strength is augmented during abstinence, this plasticity is reversed by a single reexposure to cocaine (Kourrich et al., 2007). These changes in plasticity have been linked in large part to dynamic alterations in synaptic AMPAR-mediated signaling (Kourrich et al., 2007; Rothwell et al., 2011; Jedynak et al., 2016). Previous work has shown that repeated (3-5 daily injections) of higher-dose cocaine $(15-20 \mathrm{mg} / \mathrm{kg})$ enhances synaptic strength. Initial studies investigated whether two cocaine pairings at a lower dose $(7.5 \mathrm{mg} / \mathrm{kg})$ of cocaine produced similar increases in synaptic strength, and whether a challenge injection induced "depotentiation" that has been observed $24 \mathrm{~h}$ following drug reexposure (Boudreau et al., 2007; Kourrich et al., 2007; Pascoli et al., 2011; Rothwell et al., 2011). This study contained three experimental groups, one group conditioned with cocaine and later receiving a cocaine priming injection before reinstatement testing ( $\mathrm{Coc}-\mathrm{Coc}$ ), a second group conditioned with cocaine and later receiving a saline injection before reinstatement (Coc-Sal), and a third group that only received saline injections throughout conditioning and testing (Sal-Sal). Mice treated with cocaine showed a robust place preference for the cocaine-paired context (Fig. $1 B$; ANOVA for preference test: $F_{(2,29)}=7.994, p=0.0017$ ), with post hoc tests confirming a significant difference between Coc-Coc and Sal-Sal $\left(340.30 \pm 40.69\right.$ vs $50.95 \pm 70.35, t_{(29)}=$ 4.023, $p=0.0011$ ) and a difference between Coc-Sal and Sal-Sal $\left(300.10 \pm 41.14\right.$ vs $\left.50.95 \pm 70.35 ; t_{(29)}=3.467, p=0.005\right)$. This preference was readily extinguished in both cocaine-conditioned groups (Fig. 1B). Each group was analyzed with an repeatedmeasures ANOVA across all four tests (Coc-Coc: $F_{(3,11)}=16.5$, $p<0.0001$; Coc-Sal: $\left.F_{(3,11)}=14.18, p<0.0001\right)$. Significant differences were found in the comparison between preference 
A

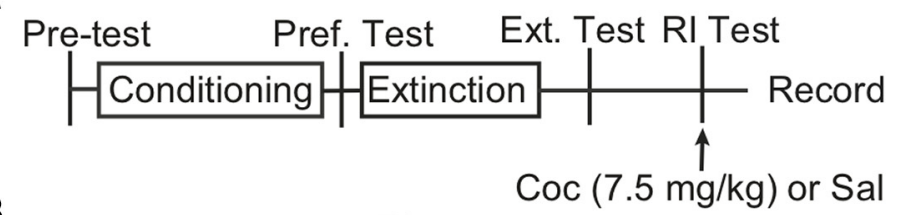

B

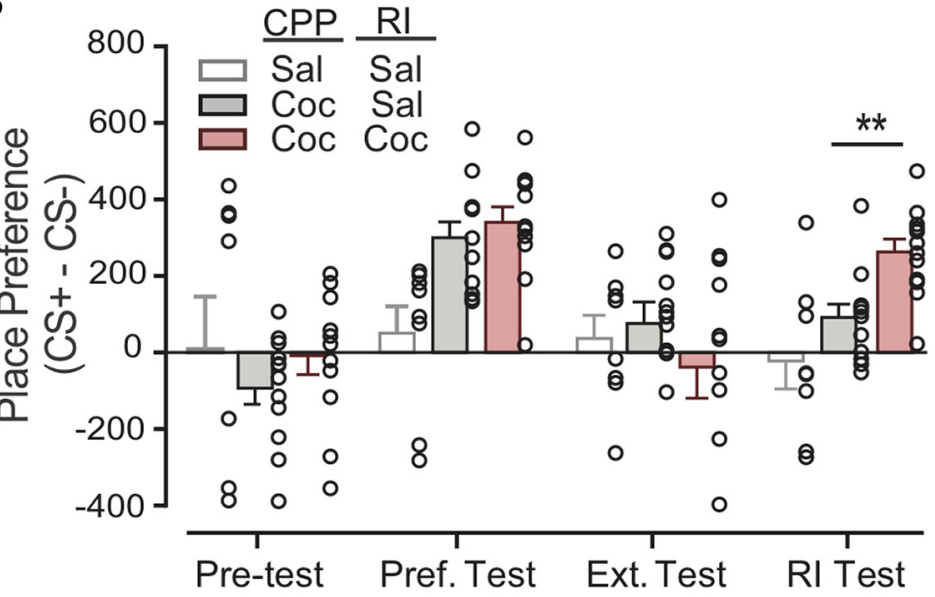

C

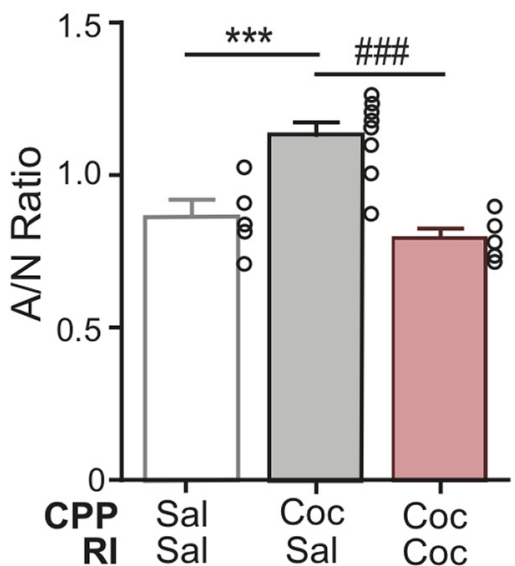

D

E

\section{Sal-Sal}

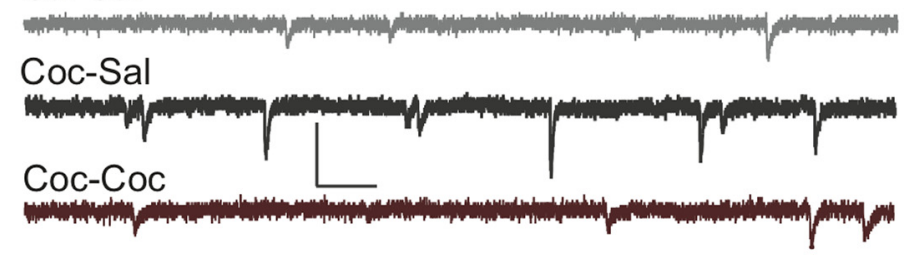

$\mathbf{F}$

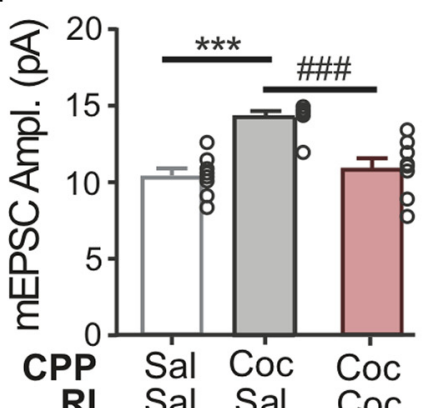

RI Sal Sal Coc

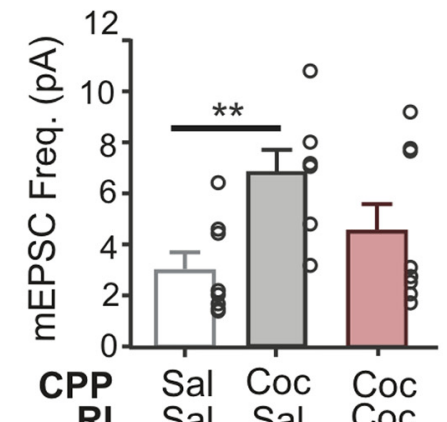

Figure 1. Bidirectional changes in AMPAR-mediated synaptic transmission in the NAc shell. $\boldsymbol{A}$, Schematic of behavioral testing and electrophysiology timeline. $\boldsymbol{B}$, Place preference results showing no Pretest chamber bias (Pre test), significant induction of place preference (Pref. Test), subsequent extinction of preference (Ext. Test), and reinstatement (RI Test) in cocaine-conditioned mice receiving a cocaine injection before reinstatement (Coc-Coc; red) compared with saline-conditioned controls (Sal-Sal, white) test and extinction test for both Coc-Coc $\left(340.30 \pm 40.6\right.$ vs $-37.87 \pm 81.21, t_{(11)}=$ $5.202, p=0.0018)$ and Coc-Sal (300.10 \pm 41.14 vs $75.99 \pm 56.42, t_{(11)}=3.223, p=$ $0.0487)$. Finally, effective reinstatement of preference was observed in the animals that received the cocaine priming injection (Fig. 1B; ANOVA for reinstatement test: $\left.F_{(2,29)}=9.98, p=0.0005\right)$, with post hoc tests confirming a significant difference between cocaine primed and salineprimed mice $(263.32 \pm 33.55$ vs $92.02 \pm$ $\left.34.60, t_{(29)}=2.91, p=0.0206\right)$ and a significant difference between the cocaineprimed group and animals receiving saline throughout conditioning (263.32 \pm 33.55 vs $-21.85 \pm 72.73, t_{(29)}=4.33, p=$ $0.0005)$.

Acute brain slices were prepared 30-90 min following the end of behavioral testing. We measured the ratio of peak AMPAR- to NMDAR-mediated evoked synaptic currents $(\mathrm{A} / \mathrm{N})$ ratio) in whole-cell recordings from MSNs in NAc shell, and observed a significant increase in the cells from cocaine-conditioned mice receiving a saline injection before reinstatement (Coc-Sal: $1.13 \pm 0.04$ ) compared with recordings from mice conditioned with saline and receiving a saline injection before testing (Sal-Sal: $0.87 \pm 0.06)$. This augmentation in $\mathrm{A} / \mathrm{N}$ ratio was significantly decreased in cocaine-conditioned mice receiving a cocaine injection before testing (Fig. 1C; Coc-Coc: $0.79 \pm 0.03$; ANOVA: $F_{(2,18)}=$ $16.11, p<0.001)$, suggesting that reexposure to cocaine depotentiates increased synaptic strength observed during withdrawal from repeated cocaine.

\footnotetext{
and cocaine mice receiving a saline injection (Coc-Sal, gray), and reinstatement (RI Test) in cocaine mice receiving a cocaine injection compared with in cocaine-conditioned mice (gray, red) compared with saline controls ( $N=8-12$ mice/group). ${ }^{* *} p<0.01$ versus Sal-Sal controls (Dunn post hoc $t$ tests). $C$, Cocaine exposure promotes bidirectional changes in synaptic strength as measured by AMPAR/NMDAR ratios (A/N ratio), with synaptic strength increased in cocaine-conditioned mice receiving a saline injection before reinstatement (Coc-Sal, gray, $N / n=5 / 8$ ) compared with those receiving cocaine (Coc-Coc, red, $N / n=5 / 7$ ) and saline only controls (Sal-Sal, white, $N / n=3 / 5) .{ }^{* * *} p<0.001$, Sal-Sal versus Coc-Sal. ${ }^{\# \#} p<0.0001$, Coc-Sal versus Coc-Coc (Newman-Keuls multiple comparison). D, Example evoked NMDAR- (black) and AMPAR-current (gray, black, red) traces. Calibration: 100 pA, 50 ms. E, Example mEPSC traces under each test condition. Calibration: 20 pA, 100 ms. $\boldsymbol{F}$, Changes in mEPSCs reflect the same bidirectional changes in synaptic transmission observed with the evoked currents. ${ }^{* *} p<0.01$, Sal-Sal versus Coc-Sal. ${ }^{* * *} p<0.001$, Sal-Sal versus Coc-Sal. ${ }^{\# \# \#} p<0.001$, CocSal versus Coc-Coc (Newman-Keuls post hoc t test).
} 
To further examine the plasticity responsible for the bidirectional shift in synaptic strength produced by a cocaine challenge, we assessed alterations in AMPAR-mediated mEPSCs (Fig. $1 F$ ). Cocaine-conditioning produced a significant increase in mEPSC amplitude compared with saline controls (amplitude ( $p A)$ : Coc-Sal (14.26 \pm 0.39); Sal-Sal (10.50 \pm 0.47 ) that was reversed by cocaine reexposure (Coc-Coc: $11.02 \pm 0.66$; ANOVA: $\left.F_{(2,22)}=14.16, p<0.001\right)$. Post hoc analysis revealed that the frequency $(\mathrm{Hz})$ of mEPSC events was increased in Coc-Sal $(6.96 \pm 0.91)$ mice compared with Sal-Sal controls $(3.11 \pm 0.66)$, but not compared with cocainereexposed mice (Coc-Coc: $4.67 \pm 1.08$; ANOVA: $F_{(2,22)}=$ $4.48, p<0.03)$. Together, these data indicate that two conditioned exposures to a lower dose of cocaine are sufficient to augment AMPAR signaling that was previously observed with $3-5$ daily injections of $15-20 \mathrm{mg} / \mathrm{kg}$ cocaine, and that reexposure to cocaine reverses select aspects of AMPAR signaling (i.e., mEPSC amplitude) (Kourrich et al., 2007; Rothwell et al., 2011; Jedynak et al., 2016).

\section{Inhibiting endocytosis of AMPARs in the NAc shell prevents cocaine-primed reinstatement of place preference}

Inhibiting endocytosis of NAc GluA2-containing AMPARs has been shown to disrupt amphetamine-induced sensitization and attenuate cocaine-induced reinstatement of cocaine-seeking (Brebner et al., 2005; Famous et al., 2008), suggesting that depotentiation of synaptic AMPAR signaling is a critical step in driving cocaine-related behavior following drug reexposure. Therefore, we next examined whether the cocaine-induced depotentiation of AMPAR signaling involves receptor endocytosis and whether this plasticity is causally involved in reinstatement of reward behavior. In these experiments, all mice were initially conditioned with cocaine. One hour before a cocaine or saline reinstatement injection, mice were intracranially infused with the active (Tat-GluA2 $2_{3 Y}$ ) or inactive (Tat-GluA2 ${ }_{3 \mathrm{~A}}$ ) isoform of a synthetic peptide which specifically blocks synaptic activitydependent, but not constitutive, AMPAR endocytosis (Brebner et al., 2005). Cocaine-primed reinstatement of preference was inhibited by blocking AMPAR endocytosis with Tat-GluA2 $2_{3 Y}$ (Fig. 2B). Two-way ANOVA revealed a significant interaction of drug treatment $\times$ peptide treatment $\left(F_{(1,68)}=8.183, p=\right.$ 0.0056). Post hoc analysis showed that mice infused with the inactive Tat-GluA2 $2_{3 \mathrm{~A}}$ peptide (Coc-Tat-GluA2 ${ }_{3 \mathrm{~A}}$ ) displayed a robust reinstatement of preference when given a cocaine injection compared with a saline injection (Sal-Tat-GluA2 $\left.{ }_{3 \mathrm{~A}}\right)(300.7 \pm$ 57.7 vs $\left.35.1 \pm 62.2 ; t_{(68)}=3.093, p=0.0172\right)$. Alternatively, mice infused with the active Tat-GluA2 $2_{3 Y}$ peptide receiving a cocaine injection (Coc-Tat-GluA2 ${ }_{3 Y} ; 24.7 \pm 65.9$ ) showed significant inhibition of reinstatement of preference compared with their inactive peptide control counterparts, Coc-Tat-GluA2 $2_{3 \mathrm{~A}}\left(t_{(68)}=\right.$ $3.376, p=0.0073)$. Approximately $30-90 \mathrm{~min}$ following testing, ex vivo analysis of mEPSCs (Fig. $2 D, E$ ) showed that cocaine reexposure produced a significant reduction in MSN mEPSC amplitude in mice infused with the inactive peptide (Coc-TatGluA2$_{3 \mathrm{~A}}: 10.29 \pm 0.34$ ), but not in those infused with the active Tat-GluA2 $2_{3 \mathrm{Y}}$ (Coc-Tat-GluA2 $\left.3 \mathrm{Y}: 15.00 \pm 0.94\right)$ compared with mice infused with the active Tat-GluA2 $2_{3 Y}$ peptide receiving an injection of saline (Sal-Tat-GluA2 $3 \mathrm{Y}$ : $13.95 \pm 0.47$; ANOVA: $\left.F_{(2,38)}=11.57, p<0.001\right)$. No significant effect was observed on mEPSC frequency.

As we have previously shown that a cocaine challenge injection also promotes depotentiation of synaptic strength within the
NAc core following abstinence (Jedynak et al., 2016), we next examined whether this plasticity also plays a role in reinstatement of place preference (Fig. 2F). Unlike the NAc shell, mice receiving either the inactive and active Tat-peptide showed significant reinstatement following a cocaine challenge injection compared with saline controls (two-way ANOVA: main effect of drug: $\left.F_{(1,42)}=14.26, p=0.0005\right)$. Together, these data indicate that internalization of GluA2-containing AMPARs in the NAc shell are required for cocaine challenge-induced depotentiation of synaptic strength, and that this plasticity selectively within the NAc shell drives cocaine-induced reinstatement of place preference.

\section{mGluR5 signaling is required for the induction of cocaine- primed reinstatement and depotentiation of NAc shell AMPAR signaling}

In the NAc shell, activation of mGluR5 receptor signaling increases phosphorylation of the endocytosis-linked Ser880 residue of GluA2 AMPARs and is sufficient to evoke cocaine-seeking (Schmidt et al., 2013). While these data strongly indicate a role for mGluR5-dependent AMPAR synaptic depression in driving reinstatement behavior, direct evidence connecting this plasticity is lacking. In these experiments, all mice were conditioned with cocaine and received an injection of cocaine before reinstatement testing (Fig. 3A). Cocaine-conditioned mice were divided into treatment groups receiving a bilateral intra-NAc shell infusion of vehicle (Veh) or MTEP (1.0 or $3.0 \mu \mathrm{g} / \mathrm{side}$ ) $15 \mathrm{~min}$ before challenge with saline. MTEP produced a dose-dependent decrease in cocaine primed reinstatement [Fig. 3C; two-way ANOVA (drug infusion $\times$ drug injection interaction): $F_{(2,52)}=3.317, p=$ $0.0441]$, which showed a significant reduction in place preference in the cocaine-primed mice receiving an infusion of $3.0 \mu \mathrm{g} / \mathrm{side}$ compared with vehicle infusion (MTEP 3.0: $100.4 \pm 67.4$ vs Veh: $\left.314.0 \pm 42.6 ; t_{(52)}=2.67, p=0.03\right)$. No reduction in cocaineprimed reinstatement was observed with the $1.0 \mu \mathrm{g} /$ side infusion of MTEP.

MTEP $(3.0 \mu \mathrm{g})$ blockade of reinstatement coincided with blockade of cocaine challenge-induced depotentiation of $\mathrm{A} / \mathrm{N}$ ratios (one-way ANOVA: $F_{(4,27)}=5.53, p=0.003$ ) at NAc shell MSN synapses (Fig. $3 C$ ). Cocaine increased ratios in cells from cocaine-conditioned mice receiving a vehicle infusion and saline reinstatement injection $(\mathrm{Coc} / \mathrm{Veh} / \mathrm{Sal}: 1.23 \pm 0.05)$ compared with saline-conditioned controls (Sal/Veh/Sal: $0.871 \pm 0.06$ ) and cocaine-treated mice receiving vehicle and a cocaine reinstatement injection (Coc/Veh/Coc: $0.79 \pm 0.03)$. Ratios from cocaine-conditioned mice receiving an infusion of MTEP ( $3 \mu \mathrm{g} /$ side) followed by a saline (Coc/MTEP/Sal: $1.18 \pm 0.14)$ or cocaine injection (Coc/MTEP/Coc: $1.17 \pm 0.06)$ were also elevated compared with Sal/Veh/Sal and $\mathrm{Coc} / \mathrm{Veh} / \mathrm{Coc}$ groups. Examination of mEPSCs indicated that the effects of MTEP are largely due to inhibition of challenge-induced reductions in AMPAR transmission, as mEPSC amplitude (Coc/Veh/-Coc: $9.37 \pm 0.34$; Coc/ MTEP/Coc: $\left.12.85 \pm 0.33 ; t_{(15)}=-6.75, p<0.001\right)$ and frequency (Coc/MTEP/Coc: $8.43 \pm 1.48$; Coc/Veh/Coc: $9.37 \pm$ $\left.0.33 ; t_{(15)}=-5.01, p=0.028\right)$ were significantly elevated in cocaine-treated mice receiving an infusion of MTEP compared with vehicle. These data show that activation of mGluR5 signaling in the NAc shell is necessary for cocaine challenge-induced depotentiation of AMPAR signaling and reinstatement of cocaine place preference. 

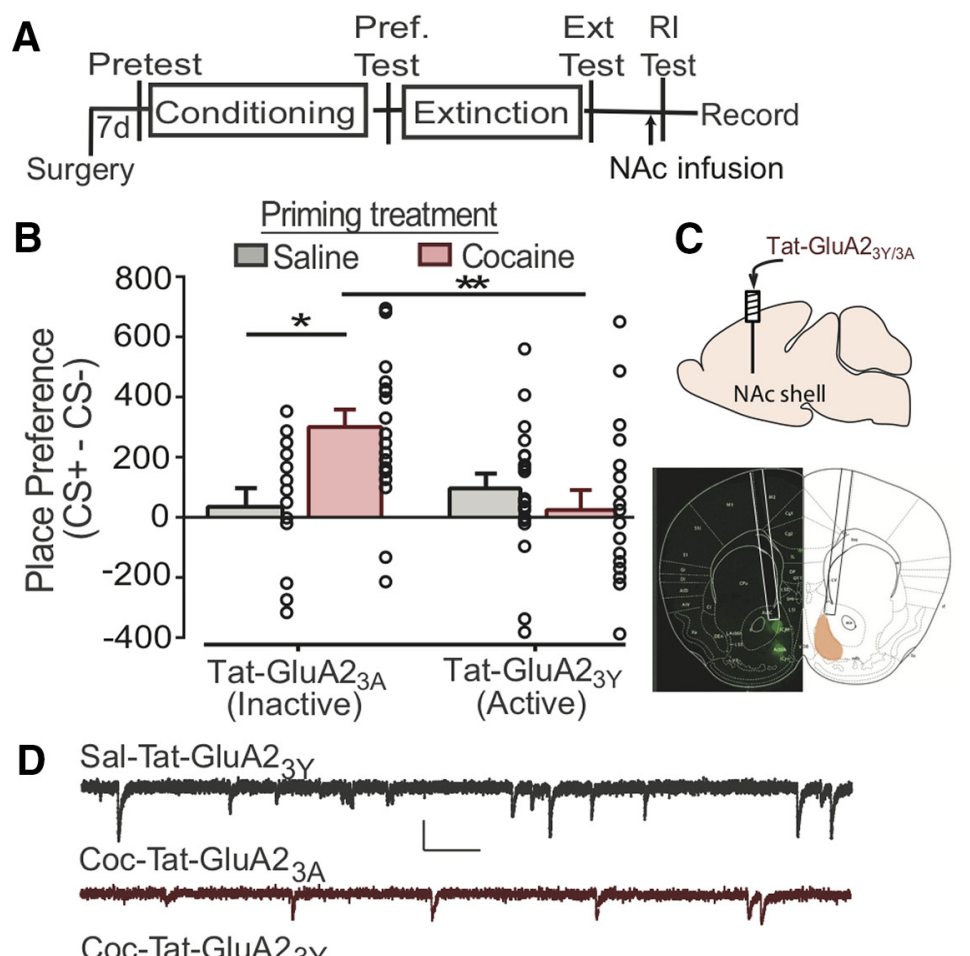

E
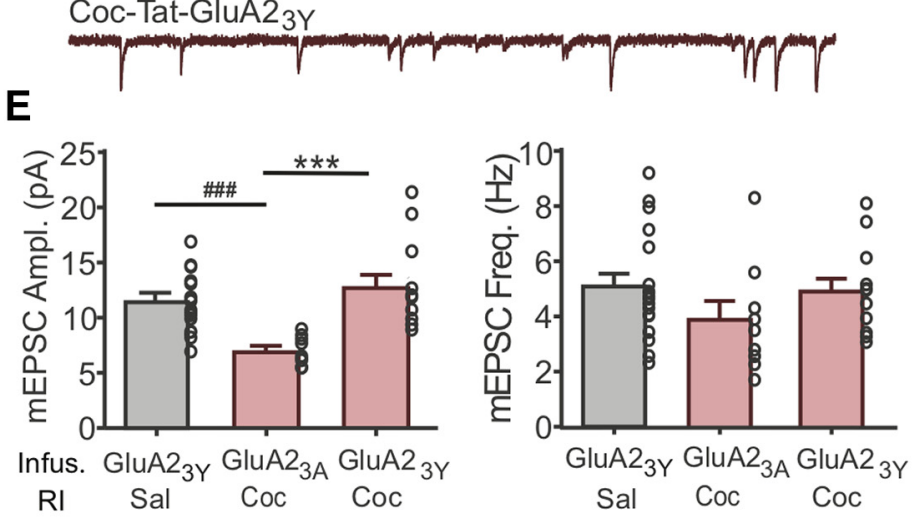$$
\mathbf{F}
$$
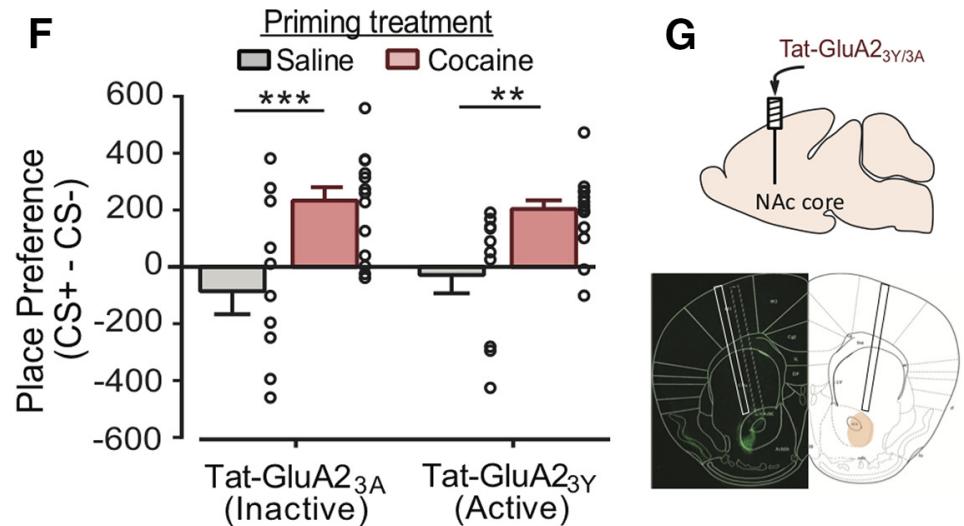

Figure 2. Inhibiting endocytosis of AMPARs in the NAc shell prevents cocaine-primed reinstatement of place preference. $\boldsymbol{A}$, Schematic of behavioral testing and electrophysiology timeline. All animals in this experiment were given cocaine during conditioning. $\boldsymbol{B}$, Behavioral results for the reinstatement test showing significant preference in the cocaine-injected mice receiving the inactive (Tat-GluA2 $2_{3 A}$, red open) peptide and blockade of cocaine-primed reinstatement by the active (Tat-GluA2 $2_{3 \gamma}$, red filled) peptide ( $N=15-20 /$ group). ${ }^{*} p<0.05$, Coc-Tat-GluA2 $3 \mathrm{~A}$ versus Sal-Tat-GluA2 $3 \mathrm{~A}$ (Bonferroni post hoc $t$ test). ${ }^{* *} p<0.01$, $\mathrm{Coc}-$ Tat-GluA2 $2_{3 Y}$ versus Coc-Tat-GluA2 $3 \mathrm{~A}$ (Bonferroni post hoc $t$ test). All drug treatments indicated in figures refer to those performed immediately before reinstatement testing. $\boldsymbol{C}$, Depiction of the cannulation and injection strategy and image illustrating the cannula path and fluorescent peptide localization (left) with an example atlas image indicating the targeting of the NAc shell for injection and physiological records (right; orange represents NAc shell). $D$, Example traces showing the mEPSCs under each test condition. Calibration: 10 pA, $100 \mathrm{~ms}$. $\boldsymbol{E}$, In vivo infusion of the Tat-GluA2 $3 \mathrm{Y}$
Selective activation of mGluR5 in the accumbens shell reinstates cocaine place preference and depotentiates AMPAR signaling

We next assessed whether select activation of mGluR5 signaling in the NAc shell is sufficient to reinstate place preference in the absence of a cocaine-priming injection. In a separate experiment, all mice were conditioned with cocaine and received a subsequent intrashell infusion of vehicle, or the selective mGluR5 agonist, CHPG $(1,3$, or $6 \mu \mathrm{g} /$ side $)$ immediately before being placed into the place preference testing apparatus (Fig. 4A). CHPG reinstated place preference in a dose-dependent manner (Fig. 4B; ANOVA: $\left.F_{(3,45)}=2.884, p=0.046\right)$, with significant preference observed only with a $6 \mu \mathrm{g}$ dose compared with the vehicle infusion (CHPG 6.0: $396.1 \pm$ 102.1 vs Veh: $-2.5 \pm 116.4 ; \mathrm{q}_{(45)}=$ 2.673, $p=0.028$ ). As individual mice received only one infusion, electrophysiological analysis of AMPAR-dependent mEPSCs was performed 30-90 min following reinstatement testing to assess whether reinstatement coincided with reductions in AMPAR signaling. Infusion of CHPG $6 \mu \mathrm{g} /$ side produced a significant reduction in mEPSC amplitude (CHPG: $9.81 \pm 0.43$, VEH: $13.97 \pm$ 0.93; Mann-Whitney $U=4.00, p<$ 0.001 ) and frequency (CHPG: $3.95 \pm$ 0.35, VEH: $5.76 \pm 0.66$; Mann-Whitney $U=24.00, p=0.018)$ compared with vehicle controls (Fig. 4D). Combined with the above data, these findings demonstrate that activation of mGluR5 signaling is not only necessary, but sufficient to drive depotentiation of synaptic AMPAR signaling and promote reinstatement of cocaine place preference, even in the absence of cocaine.

\section{$\leftarrow$}

peptide blocked cocaine evoked depotentiation of the amplitude ( $N=4-7 /$ group, $n=9-18 /$ group), with no ef-

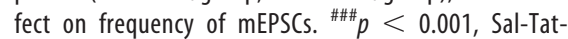
$\mathrm{GluA2}_{3 \mathrm{Y}}$ versus Coc-Tat-GluA2 ${ }_{3 \mathrm{~A}}$ (Newman-Keuls post hoc $t$ test). ${ }^{* *} p<0.001$, Coc-Tat-GluA2 3 A versus Coc-Tat$\mathrm{GluA2}_{3 \mathrm{Y}}$ (Newman-Keuls post hoc $t$ test). F, Behavioral results for the reinstatement test showing no effect of either the inactive (Tat-GluA2 $2_{3 \mathrm{~A}}$ ) peptide or active (Tat-GluA2 ${ }_{3 \mathrm{Y}}$ ) peptide infused into the NAc core on cocaine-primed reinstatement. ${ }^{*} p<0.05$, Coc versus Sal within Tat-GluA2 $2_{3 A}$ and Tat-GluA2 $2_{3 Y}$ groups (Bonferroni post hoc $t$ test). All drug treatments indicated in figures refer to those performed immediately before reinstatement testing. G, Depiction of the cannulation and injection strategy and image illustrating the cannula path and fluorescent peptide localization (left) with an example atlas image indicating the targeting of the NAC core for injection and physiological records (right; orange represents NAc core). 
A
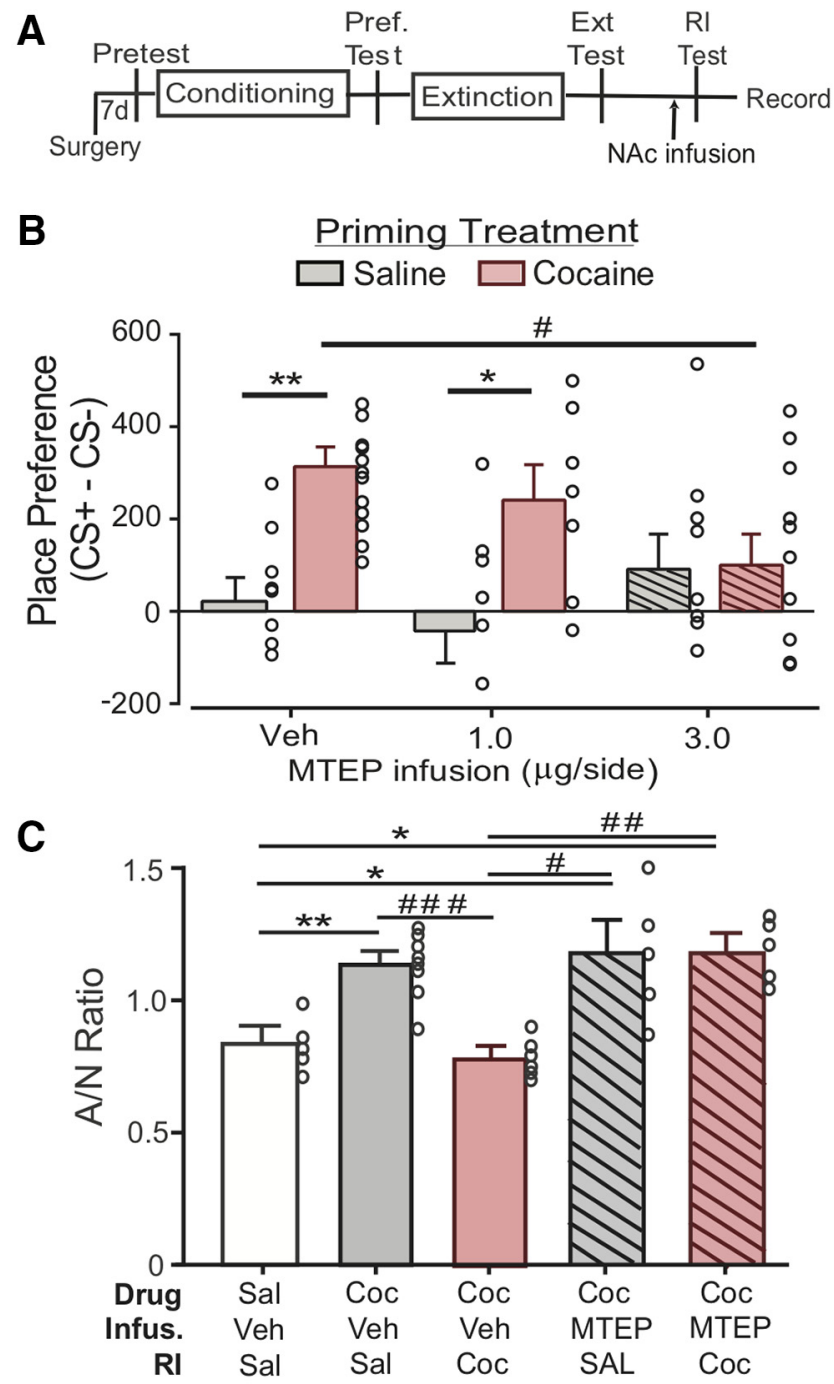

D Coc-Veh-Coc

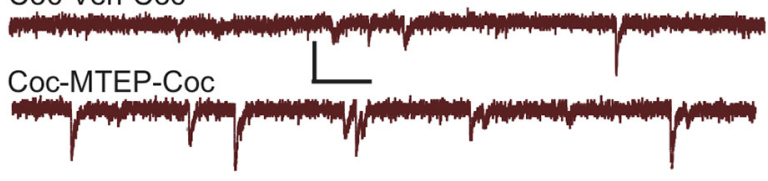

E

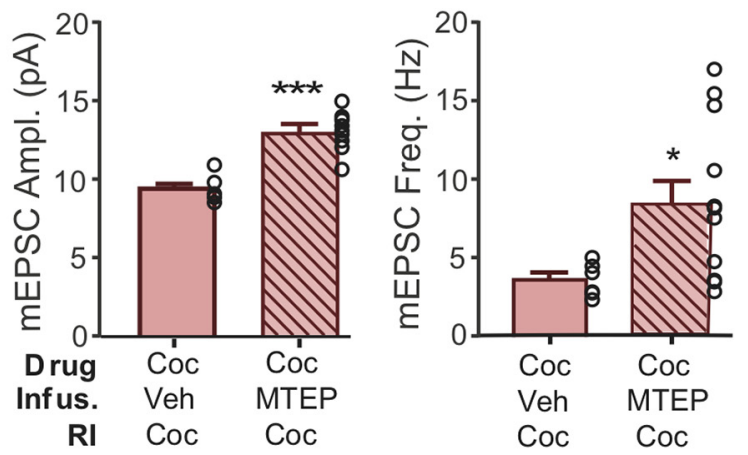

Figure 3. mGluR5 signaling is required for the induction of cocaine-primed reinstatement and depotentiation of NAc shell AMPAR signaling. $A$, Schematic of behavioral testing and electrophysiology timeline. $\boldsymbol{B}$, Behavioral results for the reinstatement test showing significant preference following cocaine treatment in the vehicle (Veh)-infused group, and a prominent inhibition of reinstatement behavior in the cocaine-primed group infused with $3.0 \mu \mathrm{g} / \mathrm{side}$ of MTEP ( $N=7-13 /$ group). ${ }^{* *} p<0.001$, saline versus cocaine-primed groups for the same MTEP/vehicle treatment. ${ }^{*} p<0.05$, saline versus cocaine-primed groups for the same MTEP/ vehicle treatment. ${ }^{*} p<0.05$, Veh versus MTEP 3.0 groups that received the cocaine priming treatment (Bonferroni post hoc $t$ test). C, mGluR5 blockade with MTEP inhibits cocaine-evoked
Infralimbic cortex-to-NAc shell neural activity controls changes in synaptic strength and triggers reinstatement The ability of mGluR5 activation and antagonism to promote and prevent reinstatement of place preference, respectively, identifies this plasticity as a potential mechanism underlying the expression of conditioned reward. However, an essential step in determining the functional role of this plasticity is elucidating the selectivity of these adaptations for specific afferent populations. While MSNs of the NAc shell receive coordinated glutamatergic input from numerous brain regions (Zahm, 2000), recent work has highlighted plasticity within afferent projections arising from the ventromedial region of the mPFC in behavioral plasticity induced by cocaine (Pascoli et al., 2011). To investigate the extent to which this pathway is involved in AMPAR-mediated depotentiation and reinstatement, we applied ex vivo and in vivo LTD protocols at ILC-to-NAc shell synapses using an optogenetic strategy involving infection of ILC with ChR2-expressing AAV and appropriately timed pulses of blue light in NAc shell (Sweis et al., 2018). Optical stimulation parameters were derived from electrical (Grueter et al., 2010) and optical (Pascoli et al., 2014) approaches in NAc MSNs that were previously shown to promote mGluR5-dependent LTD and normalization of pathway-specific cocaine plasticity, respectively. As synaptic activity is required for these experiments, initial ex vivo experiments examined sEPSCs rather than mEPSCs. This approach also permitted a within-cell examination of plasticity before and after stimulation of ILCto-NAc shell synapses and avoided confounds of multiple applications of an NMDAR antagonist. Similar to previous ex vivo (bath-applied) approaches identifying mechanisms responsible for cocaine challenge-induced depotentiation of AMPARmediated EPSCs (Jedynak et al., 2016), prior application of MTEP $(5 \mu \mathrm{M})$ blocked optically induced reductions in sEPSC amplitude [Fig. 5 I, J; Coc/ACSF (Pre: $13.99 \pm 0.86$, Post: $11.06 \pm$ $0.86)$, Coc/MTEP [Pre: $13.18 \pm 0.93$, Post: $13.01 \pm 0.93$ ); twoway repeated-measures ANOVA (drug $\times$ stimulation interaction): $F_{(1,25)}=5.65, p=0.037$ ], indicating that $10 \mathrm{~Hz}$ optical stimulation promotes an mGluR5-dependent suppression of postsynaptic AMPAR transmission.

To test whether optogenetic protocols were efficient in normalizing cocaine-evoked plasticity when applied in vivo, a similar within-subject approach was used where mice were conditioned with cocaine or saline and underwent 2 separate testing days, the first of which all mice received no stimulation (light-off), followed by Test 2, where mice received optical stimulation (465 $\mathrm{nm}, 10 \mathrm{~Hz}, 5 \mathrm{~ms}$ pulse width). To ensure that differences in plasticity between saline and cocaine mice did not reflect optically induced LTD (i.e., cocaine sufficiently upregulated transmission at these synapses), an additional group of saline-conditioned mice also received no stimulation on Test 2. Following reinstatement Test 2, optical stimulation had no apparent effect on $\mathrm{A} / \mathrm{N}$ ratios in saline mice compared with nonstimulated counterparts; however, stimulation in cocaine-conditioned mice resulted in

depotentiation of synaptic strength as measured by AMPAR/NMDAR (A/N) ratios ( $N=4-6$ / group, $n=5-8$ /group). ${ }^{*} p<0.05$ versus Sal-Veh-Sal. ${ }^{* *} p<0.01$ versus Sal-Veh-Sal. ${ }^{*} p<$ 0.05 versus Coc-Veh-Coc (Newman-Keuls post hoc $t$ test). ${ }^{\# \#} p<0.01$ versus Coc-Veh-Coc (Newman-Keuls post hoc $t$ test). ${ }^{\# \#} p<0.001$ versus Coc-Veh-Coc (Newman-Keuls post hoct test). $\boldsymbol{D}$, Example traces showing the mEPSCs under each test condition. Calibration: 10 pA, 100 ms. $\boldsymbol{E}$, In vivo infusion of the MTEP $(3.0 \mu \mathrm{g})$ increased the amplitude and frequency of mEPSCs in cells from mice primed with cocaine ( $N=5-6 /$ group; $n=6-11 /$ group). ${ }^{*} p<0.05$, Coc-MTEP-Coc versus Coc-Veh-Coc (Student's $t$ test). ${ }^{* * *} p<0.001$, Coc-MTEP-Coc versus CocVeh-Coc (Student's $t$ test). 
A
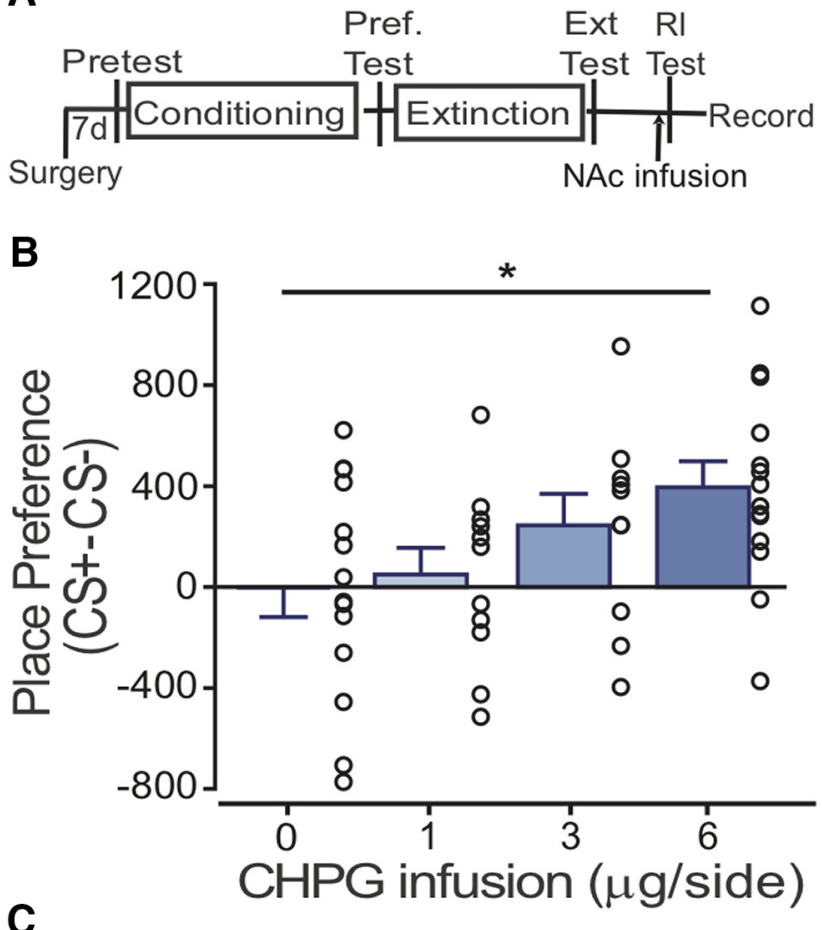

Coc-Veh

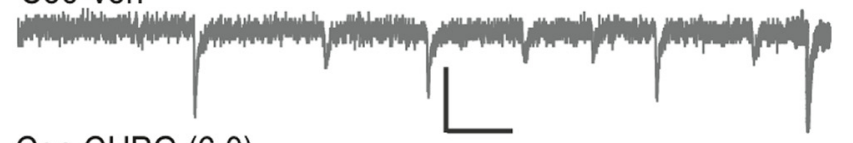

Coc-CHPG (6.0)

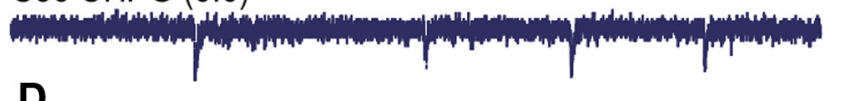

D
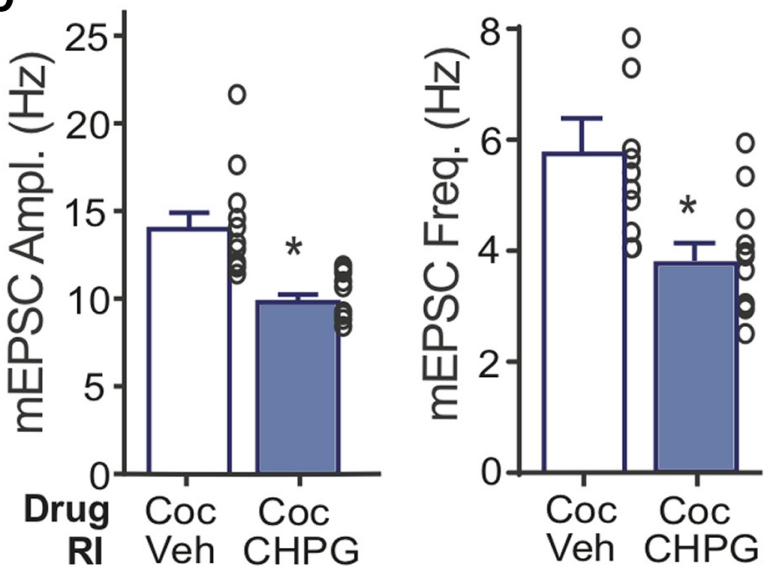

Figure 4. Selective activation of $m G$ luR 5 in the NAc shell reinstates cocaine place preference and depotentiates AMPAR signaling. $A$, Schematic of behavioral testing and electrophysiology timeline. $\boldsymbol{B}$, Behavioral results for the reinstatement test showing dose-response relationship for CHPG-induced reinstatement of cocaine place preference ( $N=11-14 /$ group). ${ }^{*} p<0.05$, vehicle versus $6.0 \mu \mathrm{g} / \mathrm{side}$ infusion group (Dunnett post hoc $t$ test). $C$, Example traces showing the mEPSCs under each test condition. Calibration: $10 \mathrm{pA}, 100 \mathrm{~ms}$. D, In vivo infusion of the CHPG $(6.0 \mu \mathrm{g} / \mathrm{side})$ reduced both the amplitude and frequency of $\mathrm{mEPSCs}(N=3$ or $4 / \mathrm{group} ; n=10$ or 11/group). ${ }^{*} p<0.05$, Coc-CHPG versus Coc-Veh (Student's $t$ test).

significantly reduced ratios compared with nonstimulated mice [Fig. $5 D, E ;$ A/N ratio (Sal/No Stim: $0.51 \pm 0.10$, Sal/Stim: $0.49 \pm$ 0.10, Coc/No Stim: $0.91 \pm 0.077$, Coc/Stim: $0.50 \pm 0.08)$; twoway ANOVA (drug $\times$ stimulation interaction): $F_{(1,20)}=4.61$, $p=0.047]$. Similar to in vivo pharmacological manipulations, significant differences in $\mathrm{A} / \mathrm{N}$ ratios aligned with increases and decreases in AMPAR-mediated transmission, as the frequency and amplitude of spontaneous EPSC were significantly greater in cocaine mice receiving no stimulation compared with saline controls and cocaine mice receiving optical stimulation [Fig. 5F, G (amplitude: Sal/No Stim: $11.24 \pm$ 0.47; Coc/No Stim: $15.78 \pm$ 1.30; Coc/Stim: $12.58 \pm 0.71$; ANOVA $\left.F_{(2,29)}=4.94, p=0.015\right)$ (frequency: Sal/No Stim: $4.16 \pm 0.16$, Coc/No Stim: $8.86 \pm 1.28$, Coc/No Stim: $4.53 \pm 0.58$; ANOVA: $\left.\left.F_{(2,29)}=7.93, p=0.002\right)\right]$.

Using the same approach, we applied optogenetic activation protocols (ChR2) in vivo to test a causal link between drugevoked plasticity and reinstatement behavior. Optical stimulation of mice coincided with a significantly greater preference toward the cocaine paired side on day 2 of testing (i.e., reinstatement) compared with preference exhibited in the absence of optical stimulation on day 1 of testing (Fig. 5H; Opto stim: $227.3 \pm$ 64.32 vs No stim: $\left.31.7 \pm 81.52 ; t_{(12)}=3.736, p=0.0028\right)$. Further, as reinstatement of drug-seeking has been shown to rely on a transient increase in prelimbic-to-NAc core glutamate transmission (Gipson et al., 2013a,b), we examined the necessity of neural activity emanating from the ILC by injecting mice with an AAV expressing the red light-activated inhibitory opsin, Jaws (Chuong et al., 2014). Following cocaine conditioning and preference extinction, terminal inhibition of ILC-to-NAc shell activity with Jaws activation $(630 \mathrm{~nm}$, for $20 \mathrm{~min})$ blocked cocaine-primed reinstatement of preference (Fig. $5 B$; Coc-No Stim: $391.5 \pm 66.5$ vs Coc-Opto Stim: $87.7 \pm 77.8 ; t_{(37)}=2.9, p=$ $0.0187)$, whereas activation of Jaws in the absence of cocaine produced no discernable preference $(71.9 \pm 77.8)$. Together, these data indicate that activation of the ILC-to-NAc shell pathway plays a critical role in cocaine-primed reinstatement by triggering a transient mGluR5-dependent reduction in synaptic strength at NAc shell MSNs.

\section{Discussion}

While repeated in vivo cocaine increases NAc AMPARdependent synaptic strength (Kourrich et al., 2007; Conrad et al., 2008; Dobi et al., 2011; Ortinski et al., 2012; Purgianto et al., 2013; Ma et al., 2014; Terrier et al., 2016), reexposure to relapse-linked stimuli reduces strength, suggesting a potential role for the latter in relapse-related behavior (Kourrich et al., 2007, 2012; Pascoli et al., 2011, 2014; Rothwell et al., 2011; Jedynak et al., 2016; Ingebretson et al., 2018; Ebner et al., 2018). We found that cocaine priming during abstinence reduces synaptic strength in NAc shell MSNs through mGluR5-dependent endocytosis of GluA2containing AMPARs and that this process is necessary and sufficient for cocaine-primed reinstatement of CPP. Furthermore, we found that rapid reduction of synaptic strength via direct ILCNAc shell stimulation reinstates conditioned reward behavior, strengthening the case for a causal link between plasticity and behavior.

\section{NAc shell synaptic depotentiation is required for cocaine-} primed CPP reinstatement

Cocaine reexposure during abstinence depotentiates NAc shell excitatory synapses as early as 30 (ex vivo) and $120 \mathrm{~min}$ (in vivo) and for at least $24 \mathrm{~h}$ after challenge (Kourrich et al., 2007; Rothwell et al., 2011; Jedynak et al., 2016; Ebner et al., 2018). While cocaine priming can initiate both reinstatement and depotentiation, a role for the latter in the former had not been thoroughly investigated. Here, we made use of a Tat-GluA2 ${ }_{3 y}$ peptide (Ahmadian et al., 2004; Brebner et al., 2005) known to interfere with activity-dependent LTD at excitatory synapses on NAc MSNs to 
A
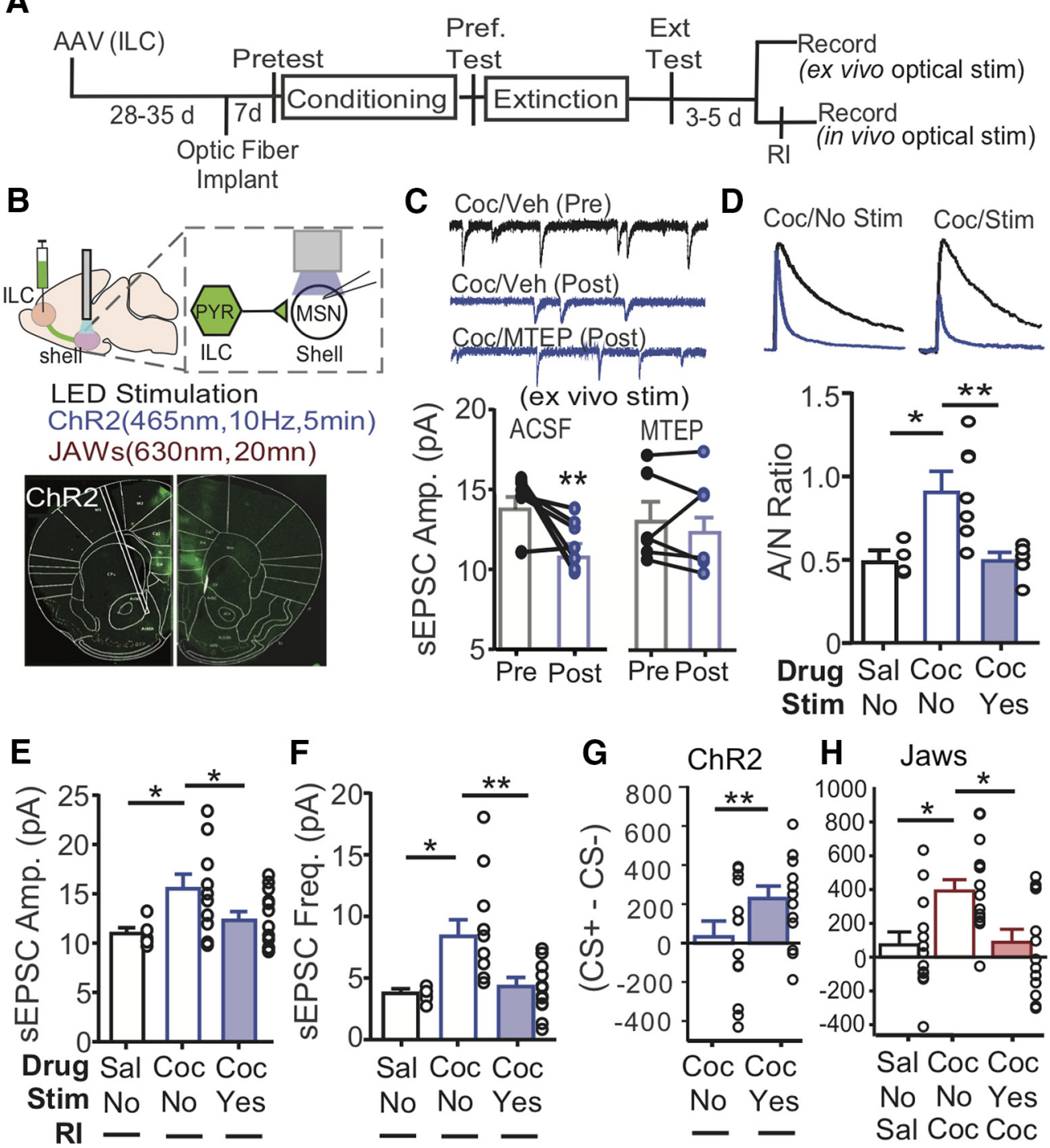

Figure 5. Infralimbic cortex-to-NAc shell neural activity controls changes in synaptic strength and triggers reinstatement. $A$, Schematic of surgeries, behavioral testing, and in vivo stimulation and ex vivo electrophysiology timeline. $\boldsymbol{B}$, Depiction of the viral infection and optic fiber implantation strategy and image illustrating optic fiber path (left) and viral fluorescence (right) in example images with atlas overlays. C, MTEP applied to the bath blocked the ability of ex vivo light-evoked stimulation (10 Hz) of ChR2 in NAc shell acute slices to evoke decreases in postsynaptic AMPAR signaling as measured by sEPSC amplitude ( $N=4$ or $5 /$ group; $n=6$ or $7 /$ group). Top, Example traces are shown for each group. ${ }^{* *} p<0.01$, prestimulation versus poststimulation (within cell) in ACSF and MTEP groups (paired Student's $t$ test). D, Cocaine increases synaptic strength (optically evoked A/N ratios) at ILC-to-NAc shell synapses (Coc-No) compared with saline-conditioned controls (Sal-No), whereas in vivo optogenetic stimulation of this pathway during reinstatement testing in the absence of a cocaine injection reduces $\mathrm{A} / \mathrm{N}$ ratios (Coc-Yes) compared with no-stim controls. ${ }^{*} p<0.05$, Coc-No stim versus Sal-No Stim (Newman-Keuls multiple comparison). ${ }^{* *} p<0.01$, Coc-No stim versus Coc-stim (Newman-Keuls multiple comparison). Top, Example traces showing the optically evoked AMPAR and NMDAR currents. Calibration: $50 \mathrm{pA}, 50 \mathrm{~ms} . \boldsymbol{E}, \boldsymbol{F}$, In vivo optogenetic stimulation of the ILC-to-NAc shell pathway reduces the amplitude and frequency of $s$ EPSCs. ${ }^{*} p<0.05$, versus Coc-No stim (Newman-Keuls multiple comparison). ${ }^{*} p<0.01$, versus Coc-No stim (Newman-Keuls multiple comparison). $\mathbf{G}$, Activation of ILC-to-NAc shell neurotransmission (10 Hz, 5 min) produces reinstatement of cocaine place preference. ${ }^{* *} p<0.01$, No stim versus Stim (Student's paired $t$ test). $\boldsymbol{H}$, Inhibition of ILC-to-NAc shell neurotransmission with optic activation of Jaws blocks cocaine-primed reinstatement of preference. ${ }^{*} p<0.05$ versus Coc-No Stim-Coc (Dunnett's post hoc $t$ test).

test this directly. We found that delivery of Tat-GluA2 $2_{3 Y}$ to NAc shell, but not core, before a cocaine-primed reinstatement test blocked both reinstatement and depotentiation. This straightforward test of the role of NAc shell synaptic depotentiation provides a robust linkage between plasticity and behavior.

\section{mGluR5 signaling is required for cocaine-primed CPP} reinstatement and depotentiation

Previous work established the importance of NAc shell Group 1 mGluR signaling in cocaine relapse-related behavior (Lee et al., 2005; Bäckström and Hyytiä, 2006; Kumaresan et al., 2009; Moussawi et al., 2009; Schmidt et al., 2013). However, a key unanswered question has been: by what means does mGluR5 activ- ity influence neural signaling in NAc shell to initiate relapserelated behavior? Given our evidence for a depotentiationreinstatement link and the fact that Group $1 \mathrm{mGluRs}$ can play a role in LTD induction (Lüscher and Huber, 2010), we tested the idea that the mGluR5-mediated effects on reinstatement might be related to NAc shell depotentiation. We found that infusion of the mGluR5 antagonist, MTEP, into the NAc shell before a cocaine-primed CPP reinstatement test blocks depotentiation of AMPAR-mediated EPSCs. This is consistent with data that support a necessity for mGluR5 activation for in vitro cocaineinduced synaptic plasticity in NAc shell MSNs from cocainetreated mice (Jedynak et al., 2016). Importantly, we also found that site-specific mGluR5 activation (via CHPG) is also sufficient, 
even in the absence of cocaine, to trigger both depotentiation and $\mathrm{CPP}$ reinstatement.

These findings add to an accumulation of evidence that mGluR5-dependent processes in NAc shell are critical for reinstatement of both cocaine-conditioned approach (present data) and self-administration (Lee et al., 2005; Bäckström and Hyytiä, 2006; Kumaresan et al., 2009). Interestingly, as with CHPG, infusion another glutamate receptor agonist, AMPA, directly into NAc immediately before behavioral testing is known to reinstate cocaine self-administration (Cornish et al., 1999; Cornish and Kalivas, 2000; Suto et al., 2004). While AMPA application is obviously a potent activator of AMPARs, it is also well known to induce a rapid and long-lasting internalization of synaptic AMPARs akin to LTD (Carroll et al., 1999; Lissin et al., 1999; Beattie et al., 2000; Ehlers, 2000). Thus, though yet to be explicitly tested, these observations draw a potential parallel to what we have observed here with mGluR5-dependent depotentiation and $\mathrm{CPP}$ reinstatement. Together, the present results strongly suggest that an endogenous source of glutamate release during cocaineprimed reinstatement induces plasticity that triggers relapserelated behavior.

\section{Depotentiation at ILC-to-NAc shell synapses reinstates cocaine CPP}

NAc shell MSNs receive glutamatergic inputs from hippocampus, thalamus, amygdala, VTA, and PFC (Finch, 1996; Stuber et al., 2010; Britt et al., 2012). Optogenetics has greatly facilitated the identification of functional roles of specific inputs in drugrelated behavior and the conditions under which these inputs exhibit drug-induced plasticity. For example, probing ILC-NAc shell inputs using optogenetics provides strong evidence for potentiation of these inputs onto MSNs following experimenter- or self-administered cocaine (Pascoli et al., 2011, 2014; Britt et al., 2012; Ma et al., 2014). Here, we extend those findings by examining a condition, after establishment and extinction of cocaine CPP, that had not yet been tested. We find that ILC-NAc shell synapses are also potentiated in this case, opening the opportunity to directly address our central question: what is the relationship between depotentiation at NAc shell glutamatergic synapses and reinstatement of cocaine $\mathrm{CPP}$ ?

Modest-frequency synaptic stimulation (e.g., 1-13 Hz) induces LTD at glutamatergic synapses on NAc MSNs (Thomas et al., 2000, 2001; Robbe et al., 2002; Grueter et al., 2010). The molecular mechanisms for LTD induction differ based on stimulation frequency. For example, $1 \mathrm{~Hz}$-generated LTD is NMDAR-dependent (Thomas et al., 2000), whereas $10 \mathrm{~Hz}$ LTD is mGluR5-dependent (Grueter et al., 2010). To build on these latter findings, we used $10 \mathrm{~Hz}$ stimulation, which induces LTD at ILC-NAc shell synapses in vivo (Sweis et al., 2018), and tested its mGluR5 dependence. This optogenetic stimulation of ILC-NAc shell projections induced depotentiation following cocaine CPP/ extinction that is blocked when delivered in the presence of the mGluR5 antagonist, MTEP. Interestingly, this stimulation is also sufficient to depress sEPSC amplitudes following in vivo and $e x$ vivo stimulation (Fig. 5C,E). As these events are of indeterminable origin (with regards to input), it is possible that ILC-NAc shell stimulation reduces excitatory drive at ILC inputs while also inducing plasticity at other inputs, consistent with previous findings (Goto and Grace, 2005; Pascoli et al., 2014).

Having established a direct, nonpharmacological means to induce mGluR5-dependent depotentiation in NAc shell following in vivo cocaine, we used it to test the relationship of this plasticity to behavior. Plasticity was induced as each subject was placed in the CPP apparatus, which is important for two reasons. First, we aimed to best approximate the timing of plasticity induction by either cocaine or the mGluR5 agonist to test our central hypothesis. Second, LTD induction via optogenetic ILC-NAc shell synaptic stimulation before testing addiction-related behavior can interfere with this behavior (Pascoli et al., 2011, 2014; Hearing et al., 2016). Here, we found that optogenetic stimulation of ILC-NAc shell inputs induced plasticity during reexposure to the CPP apparatus and reinstated cocaine CPP in the absence of drug, similar to what we observed with CHPG exposure, thus providing additional direct evidence linking NAc shell depotentiation to concurrent reinstatement of cocaine CPP.

\section{A requirement for ILC-NAc shell activation for cocaine-primed reinstatement?}

It is clear that glutamatergic neurotransmission is required for cocaine-primed reinstatement after extinction based on results with mGluR5 antagonists (Kumaresan et al., 2009; Schmidt et al., 2013) and AMPAR antagonists (Cornish et al., 1999; Cornish and Kalivas, 2000; Park et al., 2002). What is the key source of this glutamate under cocaine-priming conditions? The mPFC, including ILC, seems the most likely candidate. For example, Park et al. (2002) found that a cocaine injection directly into an mPFC region containing ILC reinstated cocaine self-administration, but failed to do so with concurrent AMPAR antagonist infusion into NAc shell. Here, we tested this directly by silencing ILC-NAc shell inputs via the inhibitory opsin, Jaws (Chuong et al., 2014). With optogenetic inhibition during cocaine injection and subsequent behavioral testing, CPP reinstatement was prevented, consistent with the idea that ILC-NAc shell inputs are a critical source of glutamate for drug-primed reinstatement and that activation of these inputs (i.e., glutamate release) is necessary for triggering the observed reduction in synaptic strength.

On one hand, the idea that silencing glutamatergic neurotransmission with AMPAR antagonists or ILC-NAc shell neurotransmission with optogenetics interferes with CPP reinstatement seems antithetical to the idea that depotentiation of AMPAR-mediated synaptic transmission in NAc shell drives reinstatement. On the other hand, there are good reasons to be cautious about assuming that diminished transmission of endogenous signals through a pathway (depotentiation) are equivalent to directly silencing that pathway. For example, glutamatergic inputs to NAc MSNs are known to functionally interact with one another in ways that produce different types of cellular (O'Donnell and Grace, 1995; Goto and Grace, 2005) and behavioral output (Goto and Grace, 2005; Pascoli et al., 2014). In this context, the fact that pathway silencing produces not a quantitative, but a qualitative effect that differs from pathway depotentiation is more logical. Clearly, the subject of information integration between glutamatergic afferent pathways in NAc neurons is ripe for further inquiry.

In conclusion, coupling these new data with previous findings yields a scenario that may unify a set of seemingly incongruent observations. A rapid, mGluR5-sensitive loss of potentiation in ILC-NAc shell AMPAR synaptic strength, while in a context to express reinstatement, is a strong positive modulator to cocaine CPP-reinstatement behavior, while dissipation of this potentiation under other conditions (e.g., optical stimulation to trigger LTD before drug reexposure) (Pascoli et al., 2011) may occlude this loss of potentiation and thus "defuse" this putative trigger for reinstatement. While plausible, this scenario raises a host of new questions, and future studies are needed to determine the extent 
to which these findings generalize to other drugs of abuse and other models for relapse-related behavior.

\section{References}

Ahmadian G, Ju W, Liu L, Wyszynski M, Lee SH, Dunah AW, Taghibiglou C, Wang Y, Lu J, Wong TP, Sheng M, Wang Y (2004) Tyrosine phosphorylation of GluR2 is required for insulin-stimulated AMPA receptor endocytosis and LTD. EMBO J 23:1040-1050.

Bäckström P, Hyytiä P (2006) Ionotropic and metabotropic glutamate receptor antagonism attenuates cue-induced cocaine seeking. Neuropsychopharmacology 31:778-786.

Beattie EC, Carroll RC, Yu X, Morishita W, Yasuda H, von Zastrow M, Malenka RC (2000) Regulation of AMPA receptor endocytosis by a signaling mechanism shared with LTD. Nat Neurosci 3:1291-1300.

Bossert JM, Marchant NJ, Calu DJ, Shaham Y (2013) The reinstatement model of drug relapse: recent neurobiological findings, emerging research topics, and translational research. Psychopharmacology 229:453-476.

Boudreau AC, Wolf ME (2005) Behavioral sensitization to cocaine is associated with increased AMPA receptor surface expression in the nucleus accumbens. J Neurosci 25:9144-9151.

Boudreau AC, Reimers JM, Milovanovic M, Wolf ME (2007) Cell surface AMPA receptors in the rat nucleus accumbens increase during cocaine withdrawal but internalize after cocaine challenge in association with altered activation of mitogen-activated protein kinases. J Neurosci 27: 10621-10635.

Brebner K, Wong TP, Liu L, Liu Y, Campsall P, Gray S, Phelps L, Phillips AG, Wang YT (2005) Nucleus accumbens long-term depression and the expression of behavioral sensitization. Science 310:1340-1343.

Britt JP, Benaliouad F, McDevitt RA, Stuber GD, Wise RA, Bonci A (2012) Synaptic and behavioral profile of multiple glutamatergic inputs to the nucleus accumbens. Neuron 76:790-803.

Carroll RC, Lissin DV, von Zastrow M, Nicoll RA, Malenka RC (1999) Rapid redistribution of glutamate receptors contributes to long-term depression in hippocampal cultures. Nat Neurosci 2:454-460.

Childress AR, Mozley PD, McElgin W, Fitzgerald J, Reivich M, O'Brien CP (1999) Limbic activation during cue-induced cocaine craving. Am J Psychiatry 156:11-18.

Chuong AS, Miri ML, Busskamp V, Matthews GA, Acker LC, Sørensen AT, Young A, Klapoetke NC, Henninger MA, Kodandaramaiah SB, Ogawa M, Ramanlal SB, Bandler RC, Allen BD, Forest CR, Chow BY, Han X, Lin Y, Tye KM, Roska B, et al. (2014) Noninvasive optical inhibition with a red-shifted microbial rhodopsin. Nat Neurosci 17:1123-1129.

Conrad KL, Tseng KY, Uejima JL, Reimers JM, Heng LJ, Shaham Y, Marinelli M, Wolf ME (2008) Formation of accumbens GluR2-lacking AMPA receptors mediates incubation of cocaine craving. Nature 454:118-121.

Cornish JL, Kalivas PW (2000) Glutamate transmission in the nucleus accumbens mediates relapse in cocaine addiction. J Neurosci 20:RC89.

Cornish JL, Duffy P, Kalivas PW (1999) A role for nucleus accumbens glutamate transmission in the relapse to cocaine-seeking behavior. Neuroscience 93:1359-1367.

Creed M, Pascoli VJ, Lüscher C (2015) Addiction therapy: refining deep brain stimulation to emulate optogenetic treatment of synaptic pathology. Science 347:659-664.

Dobi A, Seabold GK, Christensen CH, Bock R, Alvarez VA (2011) Cocaineinduced plasticity in the nucleus accumbens is cell specific and develops without prolonged withdrawal. J Neurosci 31:1895-1904.

Ebner SR, Larson EB, Hearing MC, Ingebretson AE, Thomas MJ (2018) Extinction and reinstatement of cocaine-seeking in self-administering mice is associated with bidirectional AMPAR-mediated plasticity in the nucleus accumbens shell. Neuroscience 384:340-349.

Ehlers MD (2000) Reinsertion or degradation of AMPA receptors determined by activity-dependent endocytic sorting. Neuron 28:511-525.

Ehrman RN, Robbins SJ, Childress A, O'Brien CP (1992) Conditioned responses to cocaine-related stimuli in cocaine abuse patients. Psychopharmacology 107:523529.

Famous KR, Kumaresan V, Sadri-Vakili G, Schmidt HD, Mierke DF, Cha JH, Pierce RC (2008) Phosphorylation-dependent trafficking of GluR2containing AMPA receptors in the nucleus accumbens plays a critical role in the reinstatement of cocaine seeking. J Neurosci 28:11061-11070.

Finch DM (1996) Neurophysiology of converging synaptic inputs from the rat prefrontal cortex, amygdala, midline thalamus, and hippocampal for- mation onto single neurons of the caudate/putamen and nucleus accumbens. Hippocampus 6:495-512.

Floresco SB (2007) Dopaminergic regulation of limbic-striatal interplay. J Psychiatry Neurosci 32:400-411.

Gipson CD, Kupchik YM, Shen H, Reissner KJ, Thomas CA, Kalivas PW (2013a) Relapse induced by cues predicting cocaine depends on rapid, transient synaptic potentiation. Neuron 77:867-872.

Gipson CD, Reissner KJ, Kupchik YM, Smith AC, Stankeviciute N, HensleySimon ME, Kalivas PW (2013b) Reinstatement of nicotine seeking is mediated by glutamatergic plasticity. Proc Natl Acad Sci USA 110:9124-9129.

Goto Y, Grace AA (2005) Dopamine-dependent interactions between limbic and prefrontal cortical plasticity in the nucleus accumbens: disruption by cocaine sensitization. Neuron 47:255-266.

Grueter BA, Brasnjo G, Malenka RC (2010) Postsynaptic TRPV1 triggers cell type-specific long-term depression in the nucleus accumbens. Nat Neurosci 13:1519-1525.

Hearing MC, Jedynak J, Ebner SR, Ingebretson A, Asp AJ, Fischer RA, Schmidt C, Larson EB, Thomas MJ (2016) Reversal of morphineinduced cell-type-specific synaptic plasticity in the nucleus accumbens shell blocks reinstatement. Proc Natl Acad Sci U S A 113:757-762.

Horvitz JC (2002) Dopamine gating of glutamatergic sensorimotor and incentive motivational input signals to the striatum. Behav Brain Res 137: 65-74.

Hyman SE, Malenka RC, Nestler EJ (2006) Neural mechanisms of addiction: the role of reward-related learning and memory. Annu Rev Neurosci 29:565-598.

Ingebretson AE, Hearing MC, Huffington ED, Thomas MJ (2018) Endogenous dopamine and endocannabinoid signaling mediate cocaineinduced reversal of AMPAR synaptic potentiation in the nucleus accumbens shell. Neuropharmacology 131:154-165.

Jaffe JH, Cascella NG, Kumor KM, Sherer MA (1989) Cocaine-induced cocaine craving. Psychopharmacology 97:59-64.

Jedynak J, Hearing M, Ingebretson A, Ebner SR, Kelly M, Fischer RA, Kourrich S, Thomas MJ (2016) Cocaine and amphetamine induce overlapping but distinct patterns of AMPAR plasticity in nucleus accumbens medium spiny neurons. Neuropsychopharmacology 41:464-476.

Kalivas PW, Volkow ND (2005) The neural basis of addiction: a pathology of motivation and choice. J Psychiatry 162:1403-1413.

Kourrich S, Rothwell PE, Klug JR, Thomas MJ (2007) Cocaine experience controls bidirectional synaptic plasticity in the nucleus accumbens. J Neurosci 27:7921-7928.

Kourrich S, Klug JR, Mayford M, Thomas MJ (2012) AMPAR-independent effect of striatal $\alpha$ CaMKII promotes the sensitization of cocaine reward. J Neurosci 32:6578-6586.

Kumaresan V, Yuan M, Yee J, Famous KR, Anderson SM, Schmidt HD, Pierce RC (2009) Metabotropic glutamate receptor 5 (mGluR5) antagonists attenuate cocaine priming- and cue-induced reinstatement of cocaine seeking. Behav Brain Res 202:238-244.

Lee B, Platt DM, Rowlett JK, Adewale AS, Spealman RD (2005) Attenuation of behavioral effects of cocaine by the metabotropic glutamate receptor 5 antagonist 2-methyl-6-(phenylethynyl)-pyridine in squirrel monkeys: comparison with dizocilpine. J Pharmacol Exp Ther 312:1232-1240.

Lissin DV, Carroll RC, Nicoll RA, Malenka RC, von Zastrow M (1999) Rapid, activation-induced redistribution of ionotropic glutamate receptors in cultured hippocampal neurons. J Neurosci 19:1263-1272.

Lüscher C, Huber KM (2010) Group 1 mGluR-dependent synaptic longterm depression: mechanisms and implications for circuitry and disease. Neuron 65:445-459.

Ma YY, Lee BR, Wang X, Guo C, Liu L, Cui R, Lan Y, Balcita-Pedicino JJ, Wolf ME, Sesack SR, Shaham Y, Schlüter OM, Huang YH, Dong Y (2014) Bidirectional modulation of incubation of cocaine craving by silent synapse-based remodeling of prefrontal cortex to accumbens projections. Neuron 83:1453-1467.

Moussawi K, Pacchioni A, Moran M, Olive MF, Gass JT, Lavin A, Kalivas PW (2009) N-acetylcysteine reverses cocaine-induced metaplasticity. Nat Neurosci 12:182-189.

O’Donnell P, Grace AA (1995) Synaptic interactions among excitatory afferents to nucleus accumbens neurons: hippocampal gating of prefrontal cortical input. J Neurosci 15:3622-3639.

Ortinski PI, Vassoler FM, Carlson GC, Pierce RC (2012) Temporally dependent changes in cocaine-induced synaptic plasticity in the nucleus accum- 
bens shell are reversed by D1-like dopamine receptor stimulation. Neuropsychopharmacology 37:1671-1682.

Park WK, Bari AA, Jey AR, Anderson SM, Spealman RD, Rowlett JK, Pierce RC (2002) Cocaine administered into the medial prefrontal cortex reinstates cocaine-seeking behavior by increasing AMPA receptor-mediated glutamate transmission in the nucleus accumbens. J Neurosci 22:2916-2925.

Pascoli V, Turiault M, Lüscher C (2011) Reversal of cocaine-evoked synaptic potentiation resets drug-induced adaptive behaviour. Nature 481 : 71-75.

Pascoli V, Terrier J, Espallergues J, Valjent E, O'Connor EC, Lüscher C (2014) Contrasting forms of cocaine-evoked plasticity control components of relapse. Nature 509:459-464.

Pierce RC, Wolf ME (2013) Psychostimulant-induced neuroadaptations in nucleus accumbens AMPA receptor transmission. Cold Spring Harb Perspect Med 3:a012021.

Purgianto A, Scheyer AF, Loweth JA, Ford KA, Tseng KY, Wolf ME (2013) Different adaptations in AMPA receptor transmission in the nucleus accumbens after short vs long access cocaine self-administration regimens. Neuropsychopharmacology 38:1789-1797.

Robbe D, Kopf M, Remaury A, Bockaert J, Manzoni OJ (2002) Endogenous cannabinoids mediate long-term synaptic depression in the nucleus accumbens. Proc Natl Acad Sci U S A 99:8384-8388.

Rogers JL, Ghee S, See RE (2008) The neural circuitry underlying reinstatement of heroin-seeking behavior in an animal model of relapse. Neuroscience 151:579-588.

Rothwell PE, Kourrich S, Thomas MJ (2011) Synaptic adaptations in the nucleus accumbens caused by experiences linked to relapse. Biol Psychiatry 69:1124-1126.

Schmidt HD, Schassburger RL, Guercio LA, Pierce RC (2013) Stimulation of mGluR5 in the accumbens shell promotes cocaine seeking by activating PKC gamma. J Neurosci 33:14160-14169.

Stuber GD, Hnasko TS, Britt JP, Edwards RH, Bonci A (2010) Dopaminergic terminals in the nucleus accumbens but not the dorsal striatum corelease glutamate. J Neurosci 30:8229-8233.

Suto N, Tanabe LM, Austin JD, Creekmore E, Pham CT, Vezina P (2004) Previous exposure to psychostimulants enhances the reinstatement of cocaine seeking by nucleus accumbens AMPA. Neuropsychopharmacology 29:2149-2159.

Sweis BM, Larson EB, Redish AD, Thomas MJ (2018) Altering gain of the infralimbic-to-accumbens shell circuit alters economically dissociable decision-making algorithms. Proc Natl Acad Sci U S A 115:E6347-E6355.

Terrier J, Lüscher C, Pascoli V (2016) Cell-type specific insertion of GluA2lacking AMPARs with cocaine exposure leading to sensitization, cueinduced seeking, and incubation of craving. Neuropsychopharmacology 41:1779-1789.

Thomas MJ, Beurrier C, Bonci A, Malenka RC (2001) Long-term depression in the nucleus accumbens: a neural correlate of behavioral sensitization to cocaine. Nat Neurosci 4:1217-1223.

Thomas MJ, Malenka R, Bonci A (2000) Modulation of long-term depression by dopamine in the mesolimbic system. J Neurosci 20:5581-5586.

Wydeven N, Marron Fernandez de Velasco E, Du Y, Benneyworth MA, Hearing MC, Fischer RA, Thomas MJ, Weaver CD, Wickman K (2014) Mechanisms underlying the activation of G-protein-gated inwardly rectifying K+ (GIRK) channels by the novel anxiolytic drug, ML297. Proc Natl Acad Sci USA 111:10755-10760.

Zahm DS (2000) An integrative neuroanatomical perspective on some subcortical substrates of adaptive responding with emphasis on the nucleus accumbens. Neurosci Biobehav Rev 24:85-105. 